\title{
PAPILIONOIDEA E HESPERIOIDEA (LEPIDOPTERA) DO PARQUE ESTADUAL DO MORRO DO DIABO, TEODORO SAMPAIO, SÃO PAULO, BRASIL ${ }^{1}$
}

\author{
Olaf H. H. Mielke ${ }^{2}$ \\ Mirna M. Casagrande ${ }^{2}$
}

\begin{abstract}
Papil.onoidea and Hesperioidea (Lepidoptera) of the Parque Estadual. do Morro do Diabo, Teodoro Sampaio, São Paulo, Brazil. 426 butterfly species were sampled on six field-trips to Morro do Diabo and are listed with their dates of capture and where they are recorded. A variety of collecting methods was used, including standard insect nets and traps. Adult butterflies were attracted to many substances, including, wet sand, bird droppings, excrement and decaying fruits and animals. The results were compared with anothers richest butterfly communities. The following taxonomic changes are included: Pyrrhopyge aziza subnubilus Hayward, 1935 nom. rev., stat. nov., comb. rev.; Telemiades meris meris (Plötz, 1886) sp. rev.; Quadrus u-lucida mimus (Mabille \& Boullet, 1917) nom. rev., stat. nov., Peba verames (Schaus, 1902) sp. rev., comb.n.; Peba striata Mielke, 1968, syn. nov. of Peba verames. Zonia zonia diabo ssp.n. is described.

KEY WORDS. Papilionoidea, Hesperioidea, Faunistic, Richness, Parque Estadual Morro do Diabo, São Paulo, Brazil
\end{abstract}

O estudo da riqueza das espécies de uma determinada área é de extrema importância, não só para o conhecimento histórico, como também para o conhecimento global da biodiversidade. Entre os animais, as borboletas e as aves constituem grupos de fácil visualização e também razoável identificação, conseqüentemente bons bioindicadores.

As áreas de maior riqueza lepidopterológica localizam-se, entre as poucas pesquisadas, em Cacaulândia (Rondônia, Brasil) (EMMEL \& AUsTIN 1990; AUSTIN et al. prelo), Parque Nacional del Manu - Pakitza e Área Reservada de Tambobata (Madre de Dios, Peru) (LAMAS 1981, 1983, 1985, 1994; LAMAS et al. 1991) com 1592, 1300 e 1234 espécies já identificadas, respectivamente. Todas estas áreas estão incluídas na Bacia do Alto Rio Amazonas. Os números poderão aumentar com um melhor conhecimento sistemático dos Riodinidae, Lycaenidae e Hesperiidae, onde certamente há muitas novas espécies a descrever. Em outras áreas sulamericanas já pesquisadas, a riqueza é menor, ou seja, 458 espécies na Ilha de Maracá (Roraima, Brasil) (MieLKE \& CASAGRANDE 1991 [1992]), 572 espécies em Poços

1) Contribuição número 1028 do Departamento de Zoologia, Universidade Federal do Paraná.

2) Departamento de Zoologia, Universidade Federal do Paraná. Caixa Postal 19020, 81531-990 Curitiba, Paraná, Brasil. Bolsista do CNPq.

E-mail: mibras@bio.ufpr.br 
de Caldas (Minas Gerais, Brasil (EBERT 1969) e 790 espécies em Misiones (Argentina) (CHAVES comunicação pessoal 1995). Embora as áreas comparadas sejam de tamanhos bem diversos e de esforço homem/hora de trabalho muito variado, pode-se concluir que os contrafortes dos Andes, por onde correm os rios formadores do Rio Amazonas, são os lugares de maior riqueza e biodiversidade de Lepidoptera diurna.

O objetivo deste estudo é apresentar uma lista das borboletas coletadas no Parque Estadual do Morro do Diabo, Teodoro Sampaio, São Paulo, Brasil, comparando a sua riqueza com a de outras áreas conhecidas.

\section{MATERIAL E MÉTODOS}

\section{ÁREA DE ESTUdo}

O Parque Estadual do Morro do Diabo localiza-se a oeste do Estado São Paulo sobre a margem direita do Rio Paranapanema, abrangendo uma área de 33.845 hectares entre as coordenadas de $22^{\prime \prime} 27^{\prime}$ a $22^{\prime \prime} 40$ 'S e 52 " 10 ' a 52"22'W. (Fig. 1). É a maior área de mata nativa do interior do estado. O relevo é plano a suave-ondulado, sendo quebrado pela presença do Morro do Diabo, uma elevação de $300 \mathrm{~m}$ acima dos $300 \mathrm{~m}$ da parte baixa. O clima é, segundo a classificação de Köppen, do tipo $\mathrm{Cfa}$, isto é, estação seca bem definida no inverno, temperatura média do mês mais frio menor que $18^{\circ} \mathrm{C}$ e temperatura do mês mais quente maior que $22^{\circ} \mathrm{C}$. A média anual de precipitação é de $1.131 \mathrm{~mm}$, sendo que a estação seca ocorre nos meses de abril a setembro.

A vegetação é do tipo "Floresta estacional semidecidual" (IBGE 1993), no entanto, na periferia do parque, principalmente em algumas partes às margens do Rio Paranapanema, há áreas de vegetação secundária, onde ocorrem espécies de borboletas típicas destas formações vegetais, e pequenos enclaves de matas baixas, secas com solo arenoso onde poucas espécies ocorrem. Ao redor da área do Parque há campos artificiais para pasto, com fauna típica.

As técnicas utilizadas para coleta, foram as normalmente usadas para lepidópteros, isto é, coletas manuais, percorrendo as trilhas, caminhos e o topo do Morro do Diabo durante o dia, normalmente entre 8 e 16 horas, quando poucos exemplares ainda são ativos, ocasionalmente até o crepúsculo para coletar Nymphalidae (Brassolinae) e Hesperiidae crepusculares. Os exemplares foram coletados com rede entomológica sobre a vegetação, em areia na beira do Rio Paranapanema (Porto), em excrementos de aves, mamíferos e em sapos mortos por caminhões que trafegavam dentro do Parque na retirada de madeira proveniente da derrubada para o alagamento da Hidroelétrica de Rosana, ou através de armadilhas para lepidópteros com iscas de bananas, fermentadas em caldo de cana.

Os locais utilizados para coleta foram:

1) Estrada da entrada do Parque até a Sede, de base arenosa e ladeada por mata primária.

2) Morro do Diabo, elevação de 600 metros com mata primária tanto na base como topo.

3) Estrada para os Portos no Rio Paranapanema, a partir da Ferrovia. Pouco antes 
da metade de sua extensão total, bifurca-se, o braço da direita leva ao Porto dos Guedes e o da esquerda ao Porto Angelin; este até a inundação da represa oferecia uma ampla praia, onde muitos exemplares foram coletados pousados na areia. Toda a estrada, incluindo o braço que vai ao Porto dos Guedes, apresenta várias áreas de mata primária intercaladas por áreas semi-abertas com vegetação secundária e algumas totalmente abertas.

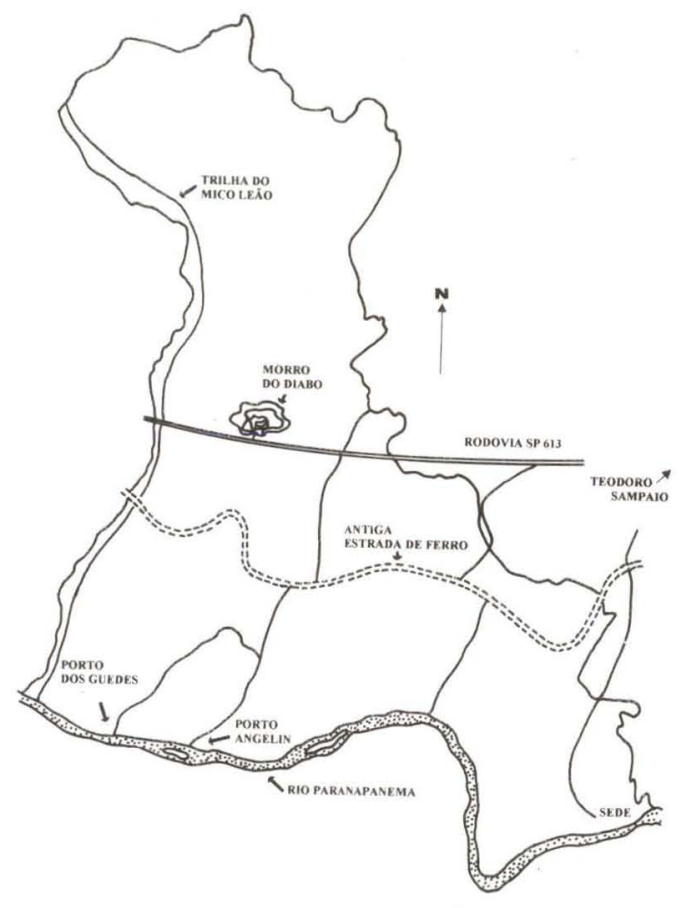

Fig. 1. Mapa do Parque Estadual do Morro do Diabo, indicando os locais de coleta.

No laboratório os exemplares foram preparados, rotulados, identificados e incluidos na Coleção de Entomologia Pe. Jesus Santiago Moure do Departamento de Zoologia, Setor de Ciências Biológicas, Universidade Federal do Paraná. Uma coleção didática foi preparada e depositada na sede do Parque. Todas as espécies citadas, foram no mínimo coletadas em uma das excursões, podendo ou não terem sido coletadas em outras, ou apenas visualizadas, mas em ambos os casos, registradas. Os critérios utilizados para definir a freqüência das espécies durante o total de coletas são os seguintes: rara, quando foram observados e/ou coletados entre um e três exemplares; escassa, entre quatro e dez exemplares e comum, acima de onze.

Ao todo foram realizadas seis excursões programadas para coletar durante quatro dias, no entanto, as chuvas prejudicaram algumas das coletas. As datas são as seguintes: 22-25-X-1987, 17-19-VIII-1989, 5-8-XII-1989, 20-23-II-1990, 2223-V-1990, 15-18-III-1991. 


\section{COMPOSIÇÃO TAXONÔMICA}

As 426 espécies coletadas mostram uma composição faunística de $46 \%$ de Hesperiidae, 30\% de Nymphalidae, 8,2\% de Lycaenidae, 7,8\% de Riodinidae, 4,4\% de Pieridae e 3,5\% de Papilionidae. Este percentual é muito diferente da mostrada para Pakitza, Tambopata e Cacaulândia (LAMAS 1994; AUSTIN et al. prelo), isto sugere uma necessidade de se ampliar este tipo de estudo no sul do país, já que os resultados apresentados mostram uma composição muito diferente quando comparada com estudos semelhantes (Tab. I).

Tabela I . Comparação entre a composição taxônomica do Parque Estadual do Morro do Diabo, Teodoro Sampaio, São Paulo, Brasil com aquelas de Cacaulândia (Rondônia, Brasil) e de Tambopata e Pakitza (Peru).

\begin{tabular}{lrrrr}
\hline Familia e subfamilia & Morro do Diabo & Cacaulândia & Tambopata & Pakitza \\
\hline Hesperiidae & 196 & 573 & 437 & 448 \\
Hesperiinae & 97 & 208 & 220 & 225 \\
Pyrginae & 89 & 326 & 191 & 197 \\
Pyrrhopyginae & 10 & 39 & 26 & 26 \\
Lycaenidae & 35 & 557 & 409 & 427 \\
Riodinidae & 33 & 345 & 239 & 246 \\
Nymphalidae & 128 & 404 & 337 & 369 \\
Apaturinae & 3 & 6 & 6 & 6 \\
Brassolinae & 11 & 17 & 22 & 22 \\
Charaxinae & 12 & 35 & 27 & 28 \\
Danainae & 3 & 6 & 3 & 4 \\
Heliconiinae & 10 & 29 & 25 & 24 \\
Ithominae & 18 & 64 & 42 & 62 \\
Libytheinae & 1 & 1 & 1 & 1 \\
Limenitidinae & 2 & 123 & 98 & 97 \\
Morphinae & 15 & 11 & 11 & 13 \\
Nymphalinae & 12 & 20 & 19 & 103 \\
Satyrinae & 15 & 92 & 83 & 25 \\
Papilionidae & 19 & 27 & 25 & 31 \\
Pieridae & 426 & 31 & 26 & 1300 \\
\hline Total de espécies & & 1592 & 1234 & \\
\hline & & & & 9 \\
\hline
\end{tabular}

\section{RESULTADOS}

Foram registradas 426 espécies, conforme listado a seguir. O primeiro número indica a posição na lista, enquanto o segundo (entre parênteses) refere-se ao número de ordem dentro da família. Logo após a citação do nome da espécie são indicados os meses em que a espécie foi vista ou coletada. Entre parênteses após superfamília, família, subfamília e tribo, estão indicados o número de espécies coletadas e/ou observadas pertinentes a cada taxa. 


\section{Papilionoidea (Latreille, 1802) Dyar, 1902 (230)}

Papilionidae (Latreille, 1802) Leach, 1819 (15)

Papilioninae (Latreille, 1802) Swainson, 1848 (15)

Troidini Ford, 1944 (3)

1(1) Parides neophilus eurybates (Gray, [1853])

Fevereiro, março, maio, agosto e outubro. Comum, em mata primária.

2(2) Parides anchises nephalion (Godart, 1819)

Fevereiro, março, outubro e dezembro. Escassa, em mata primária.

3(3) Battus polydamas polydamas (Linnaeus, 1758)

Fevereiro, março e dezembro. Comum, em áreas abertas e areia.

Papilionini (Latreille, 1802) Haase, 1892 (6)

4(4) Heraclides anchisiades capys (Hübner, [1809])

Fevereiro, março, outubro e dezembro. Comum, em mata primária e areia.

5(5) Heraclides astyalus astyalus (Godart, [1819])

Fevereiro, março, maio, agosto, outubro e dezembro. Comum, em mata primária, no topo do Morro e com maiores concentrações em areia.

6(6) Heraclides hectorides (Esper, 1794)

Fevereiro, março, agosto, outubro e dezembro. Comum, em mata primária, maiores concentrações em areia.

7(7) Heraclides thoas brasiliensis (Rothschild \& Jordan, 1906)

Fevereiro, março, agosto, outubro e dezembro. Comum, maiores concentrações em areia.

8(8) Heraclides torquatus polybius (Swainson, 1823)

Fevereiro, março, outubro e dezembro. Rara, em mata primária e areia.

9(9) Heraclides androgeus laodocus (Fabricius, 1793)

Fevereiro, março e dezembro. Escassa, maiores concentrações em areia.

Leptocircini (Kirby, 1896) Hancock, 1983 (6)

10(10) Protographium asius (Fabricius, [1782])

Outubro e dezembro. Comum, maiores concentrações em manchas de urina na borda de mata primária ao longo da estrada asfaltada (SP 613).

11(11) Protesilaus agesilaus autosilaus (Bates, 1861)

Outubro. Rara, em areia.

12(12) Protesilaus nigricornis (Staudinger, 1884)

Fevereiro. Escassa, em areia.

13(13) Protesilaus telesilaus domitor (Fruhstorfer, 1907)

Fevereiro, agosto e dezembro. Escassa, no topo do Morro e em areia.

14(14) Protesilaus stenodesmus (Rothschild \& Jordan, 1906)

Março e outubro. Escassa, em areia.

15(15) Mimoides protodamas (Godart, 1819)

Outubro. Rara, em manchas de urina na borda de mata primária, ao longo da estrada asfaltada (SP 613). 
Pieridae (Boisduval, 1829) Duponchel, 1844 (19)

Pierinae (Boisduval, 1829) Swainson, 1840 (3)

Pierini (Boisduval, 1829) Godman \& Salvin, 1889 (3)

16(1) Ascia monuste orseis (Godart, 1819)

Outubro. Escassa, em áreas abertas.

17(2) Glutophrissa drusilla drusilla (Cramer, [1777])

Fevereiro, março, maio, agosto, outubro e dezembro. Comum, em áreas abertas, mata primária e areia.

18(3) Pieriballia mandela molione (Fruhstorfer, 1908)

Fevereiro, março, maio, agosto, outubro e dezembro. Comum, em mata primária e areia.

Coliadinae (Swainson, 1827) Aurivillius, 1910 (13)

19(4) Aphrissa statira statira (Cramer, [1777])

Fevereiro, março, maio, agosto e dezembro. Comum, em mata primária, áreas abertas e areia.

20(5) Anteos clorinde (Godart, [1824])

Fevereiro, março e dezembro. Comum, em mata primária e áreas abertas.

21(6) Eurema deva deva (Doubleday, 1847)

Fevereiro e maio. Escassa, em áreas abertas e semi-abertas.

22(7) Eurema elathea flavescens (Chavannes, 1850)

Fevereiro, março e agosto. Comum, em áreas abertas.

23(8) Eurema albula albula (Cramer, [1776])

Fevereiro e agosto. Escassa, em áreas abertas e semi-abertas.

24(9) Eurema agave pallida (Chavannes, 1850)

Fevereiro. Rara, em áreas abertas próximas ao Porto.

25(10) Pyrisitia nise tenella (Boisduval, 1836)

Dezembro. Escassa, em áreas abertas próximas ao Porto.

26(11) Pyrisitia leuce leuce (Boisduval, 1836)

Fevereiro, março, maio, agosto, outubro e dezembro. Comum, em áreas semi-abertas.

27(12) Phoebis sennae marcellina (Cramer, [1777])

Fevereiro. Escassa, em areia.

28(13) Phoebis argante argante (Fabricius, 1775)

Fevereiro, março, maio, agosto e dezembro. Escassa, com ampla distribuição, isoladamente e em areia.

29(14) Phoebis philea philea (Linnaeus, 1763)

Fevereiro, março, agosto e dezembro. Escassa, com ampla distribuição, isoladamente em areia.

30(15) Phoebis neocypris (Hübner, [1823])

Fevereiro, março, agosto, outubro e dezembro. Comum, com ampla distribuição, maiores concentrações em areia. 
31(16) Rhabdodryas trite banksi F.M. Brown, 1929

Fevereiro, março, agosto e outubro. Escassa, com ampla distribuição, maiores concentrações em areia.

Dismorphiinae (Schatz, 1886) Talbot, 1932 (3)

32(17) Dismorphia amphiona astynome (Dalman, 1823)

Fevereiro e outubro. Rara, em mata primária.

33(18) Enantia lina psamathe (Fabricius, 1793)

Fevereiro e agosto. Comum, em mata primária.

34(19) Pseudopieris nehemia nehemia (Boisduval, 1836)

Agosto. Rara, em areia.

Nymphalidae (Swainson, 1827) Westwood, 1840 (128)

Danainae (Boisduval, 1832) Bates, 1861 (3)

Danaini (Boisduval, 1832) Moulton, 1908 (2)

35(1) Anosia gilippus gilippus (Cramer, [1775])

Fevereiro, maio e agosto. Comum, em áreas abertas.

36(2) Danaus plexippus erippus (Cramer, [1775])

Fevereiro, março, maio e dezembro. Comum, em áreas abertas.

Euploeini (Moore, [1880]) Scudder, 1893 (1)

37(3) Lycorea halia discreta Haensch, 1909

Fevereiro, março, agosto e dezembro. Comum, em mata primária.

Ithomiinae (Godman \& Salvin, 1879) Kirby, 1894 (18)

Tithoreini Fox, 1940 (1)

38(4) Tithorea harmonia psendethra Butler, 1873

Fevereiro, março, agosto, outubro e dezembro. Comum, em mata primária.

Mechanitini Fox, 1949 (4)

39(5) Mechanitis lysimnia lysimnia (Fabricius, 1793)

Março, maio, agosto e outubro. Comum, em mata primária.

40(6) Mechanitis polymnia casabranca Haensch, 1905

Fevereiro, março e dezembro. Comum, em mata primária.

41(7) Sais rosalia rosalinde Weymer, 1890

Agosto. Rara, em mata primária na Trilha do Mico Leão.

42(8) Thyridia psidii cetoides (Rosenberg \& Talbot, 1914)

Agosto e dezembro. Escassa, em mata primária.

Oleriini Fox, 1940 (1)

43(9) Aeria olena olena Weymer, 1875

Fevereiro, março, maio, agosto, outubro e dezembro. Comum, em mata primária.

Methonini Mielke \& Brown, 1979 (1)

44(10) Methona themisto (Hübner, 1818)

Março e agosto. Comum, em mata primária. 
Napeogenini Fox, 1949 (4)

45(11) Epityches eupompe (Geyer, 1832)

Março e maio. Comum, em mata primária.

46(12) Hypothyris euclea nina (Haensch, 1905)

Março, agosto, outubro e dezembro. Comum, em mata primária.

47(13) Hypothyris ninonia daeta (Boisduval, 1836)

Agosto. Rara, em mata primária na Trilha do Mico Leão.

48(14) Placidula euryanassa (C. Felder \& R. Felder, 1865)

Outubro. Escassa, em mata primária.

Ithomiini (Godman \& Salvin, 1879) Zerny \& Beier, 1936 (1)

49(15) İthomia agnosia zikani D'Almeida, 1940

Maio e agosto. Escassa, em mata primária na Trilha do Mico Leão.

Dircennini D'Almeida, 1941 (4)

50(16) Dircenna dero celtina Burmeister, 1878

Agosto. Escassa, em mata primária na Trilha do Mico Leão.

51(17) Episcada carcinia Schaus, 1902

Março e agosto. Comum, em mata primária.

52(18) Episcada hymenaea hymenaea (Prittwitz, 1865)

Fevereiro, março, maio, agosto e outubro. Comum, em mata primária. 53(19) Pteronymia carlia Schaus, 1902

Agosto. Rara, em mata primária na Trilha do Mico Leão.

Godyridini D'Almeida, 1941 (2)

54(20) Hypoleria salonina salonina (Hewitson, 1865)

Maio, agosto e outubro. Comum, em mata primária.

55(21) Pseudoscada erruca (Hewitson, 1855)

Maio e agosto. Escassa, em mata primária na Trilha do Mico Leão.

Brassolinae (Boisduval, 1836) Bates, 1861 (11)

Brassolini (Boisduval, 1836) Handlirsch, 1925 (9)

56(22) Blepolenis didymaon (C. Felder \& R. Felder, 1867)

Fevereiro e maio. Escassa, em áreas semi-abertas.

57(23) Brassolis sophorae vulpeculus Stichel, 1902

Dezembro. Escassa, em mata primária e áreas semi-abertas.

58(24) Caligo illioneus pampeiro Fruhstorfer, 1904

Fevereiro, março e dezembro. Comum, em áreas de mata primária.

59(25) Caligo teucer japetus Stichel, 1903

Fevereiro. Rara, em mata primária.

60(26) Catoblepia berecynthia unditaenia Fruhstorfer, 1907

Dezembro. Rara, em mata primária.

61(27) Eryphanis automedon automedon (Cramer, [1776])

Fevereiro, maio e dezembro. Comum, em mata primária, atraída para armadilhas com frutas em decomposição. 
62(28) Opsiphanes invirae amplificatus Stichel, 1904

Fevereiro, março, maio, agosto, outubro e dezembro. Comum, em mata primária, sobre animais (sapo) em decomposição, excrementos e atraída para armadilhas com frutas em decomposição.

63(29) Opsiphanes quiteria meridionalis Staudinger, 1887

Fevereiro e outubro. Escassa, em mata primária, sobre animais (sapo) em decomposição e excrementos.

64(30) Selenophanis cassiope guarany Casagrande, 1992

Fevereiro, março e dezembro. Escassa, em mata primária, no início da estrada para o Porto, machos em armadilhas com frutas em decomposição.

Naropini (Stichel, 1925) Casagrande, 1996 (2)

65(31) Narope cyllastros cyllastros Doubleday, [1849]

Fevereiro. Escassa, em mata primária, atraída para armadilhas com frutas em decomposição.

66(32) Narope panniculus panniculus Stichel, 1904

Fevereiro e outubro. Escassa, em mata primária, coletada (machos) em estrada aberta na mata para transporte de madeira, sobre carcaça de animais (sapo) em decomposição.

Morphinae (Newmnan, 1834) Butler, 1869 (2)

67(33) Iphixibia anaxibia (Esper, [1801])

Fevereiro. Rara, em mata primária na estrada para o Porto.

68(34) Morpho helenor paulista Fruhstorfer, 1907

Fevereiro, março, maio, agosto, outubro e dezembro. Comum, em mata primária.

Satyrinae (Boisduval, 1832) Bates, 1861 (12)

Euptychiini (Reuter, 1896) L. Miller, 1968 (12)

69(35) Hermeuptychia hermes (Fabricius, 1775)

Fevereiro, março, maio, agosto e dezembro. Comum, em mata primária. 70(36) Moneuptychia moneca (Schaus, 1902)

Agosto. Escassa, em mata primária na Trilha do Mico Leão, atraída para armadilhas com frutas em decomposição.

71(37) Pareuptychia interjecta (D'Almeida, 1952)

Fevereiro e março. Escassa, em mata primária, atraída para armadilhas com frutas em decomposição.

72(38) Pareuptychia summandosa (Gosse, 1880)

Março, agosto e dezembro. Comum, em mata primária, atraída para armadilhas com frutas em decomposição.

73(39) Posttaygetis penelea penelina (Staudinger, 1888)

Fevereiro, março, agosto e dezembro. Comum, em mata primária, atraída para armadilhas com frutas em decomposição. 
74(40) Splendeuptychia libitina (Butler, 1870)

Março. Rara, em mata primária.

75(41) Taygetis erubescens (Butler, 1868)

Agosto, outubro e dezembro. Comum, em mata primária, atraída em armadilha com frutas em decomposição.

76(42) Taygetis keneza celia (Cramer, [1780])

Fevereiro, março e dezembro. Comum, em mata primária, atraída para armadilhas com frutas em decomposição.

77(43) Taygetis kerea Butler, 1869

Agosto. Escassa, em mata primária atraída, em armadilhas com frutas em decomposição.

78(44) Taygetis thamyra (Cramer, 1780)

Fevereiro, março, agosto, outubro e dezembro. Comum, em mata primária, atraída para armadilhas com frutas em decomposição.

79(45) Taygetis tripunctata Weymer, 1907

Fevereiro, março, maio, outubro e dezembro. Comum, em mata primária, atraída para armadilhas com frutas em decomposição.

80(46) Zischkaia fumata (Butler, 1867)

Fevereiro, março e maio. Comum, em mata primária, atraída para armadilhas com frutas em decomposição.

Heliconiinae (Swainson, 1827) Bates, 1864 (10)

Acraeini (Boisduval, 1833) Handlirsch, 1925 (1)

81(47) Actinote carycina Jordan, 1913

Fevereiro, março, agosto, outubro e dezembro. Comum, em áreas semi-abertas.

Heliconiini (Swainson, 1827) Handlirsch, 1925 (9)

82(48) Agraulis vanillae maculosa (Stichel, 1907)

Fevereiro, março, maio e dezembro. Comum, em áreas abertas e semiabertas.

83(49) Dione juno juno (Cramer, [1780])

Dezembro. Escassa, em áreas abertas e semi-abertas.

84(50) Dryadula phaetusa (Linnaeus, 1758)

Fevereiro, março, maio e agosto. Comum, em áreas abertas.

85(51) Dryas iulia alcionea (Cramer, [1780])

Fevereiro, março, maio, agosto, outubro e dezembro. Comum, em áreas

abertas e semi-abertas

86(52) Eueides aliphera (Godart, 1819)

Fevereiro, março, maio, agosto. Comum, em mata primária.

87(53) Eueides isabella dianasa (Hübner, 1806)

Fevereiro, março e dezembro. Comum, em mata primária.

88(54) Eueides vibilia unifasciata Butler, 1873

Outubro. Escassa, em mata primária. 
89(55) Heliconius erato phyllis (Fabricius, 1775)

Fevereiro, março, maio, agosto e dezembro. Comum, em mata primária e áreas semi-abertas.

90(56) Heliconius ethilla polychrous C. Felder \& R. Felder, 1865

Fevereiro, março, maio, agosto e dezembro. Comum, em mata primária e áreas semi-abertas.

Nymphalinae (Swainson, 1827) Doubleday, 1845 (15)

Nymphalini (Swainson, 1827) Grote, 1897 (4)

91(57) Hypanartia lethe (Fabricius, 1793)

Fevereiro, março, maio, agosto, outubro e dezembro. Comum, em mata primária e áreas semi-abertas.

92(58) Hypanartia bella (Fabricius, 1793)

Maio. Rara, em áreas semi-abertas na Trilha do Mico Leão.

93(59) Vanessa braziliensis (Moore, 1883)

Agosto. Escassa, em áreas abertas.

94(60) Vanessa myrinna (Doubleday, 1849)

Maio. Escassa, em áreas semi-abertas.

Kallimini (Doherty, 1886) Reuter, 1896 (5)

95(61) Anartia amathea roeselia (Eschscholtz, 1821)

Maio e agosto. Comum, em áreas semi-abertas.

96(62) Anartia jatrophae jatrophae (Linnaeus, 1763)

Fevereiro e março. Comum, em áreas abertas.

97(63) Junonia evarete (Cramer, [1780])

Fevereiro, março e maio. Comum, em áreas abertas.

98(64) Siproeta stelenes meridionalis (Fruhstorfer, 1908)

Fevereiro, março, maio, agosto, outubro e dezembro. Comum, em mata primária.

99(65) Siproeta epaphus trayja Hübner, [1823]

Fevereiro, março, maio, outubro e dezembro. Comum, em mata primária.

Melitaeini (Newman, 1869) Grote, 1897(6)

100(66) Chlosyne lacinia saundersi (Doubleday, [1847])

Fevereiro, março, maio e agosto. Comum, em áreas semi-abertas.

101(67) Eresia lansdorfi (Godart, 1819)

Fevereiro, agosto, outubro e dezembro. Comum, em mata primária e areia.

102(68) Ortilia dicoma (Hewitson, 1864)

Fevereiro, agosto e dezembro. Comum, com maiores concentrações em areia.

103(69) Ortilia ithra (Kirby, 1900)

Fevereiro, março, maio, agosto e outubro. Comum, em mata primária. 
104(70) Tegosa orobia (Hewitson, 1864)

Fevereiro, maio, agosto, outubro e dezembro. Comum, em mata primária.

105(71) Phystis simois variegata (Röber, [1914])

Agosto. Rara, em mata primária na Trilha do Mico Leão.

Limenitidinae (Behr, 1864) L. Miller \& F. M. Brown, 1981 (41)

Coeini Scudder, 1893 (3)

106(72) Colobura dirce dirce (Linnaeus, 1758)

Fevereiro, março, agosto, outubro e dezembro. Comum, em mata primária, pousada em excrementos, carcaças de animais em decomposição e atraída para armadilhas com frutas em decomposição.

107(73) Historis odius (Fabricius, 1775)

Fevereiro, março e dezembro. Comum, em mata primária, pousada em excrementos, carcaças de animais em decomposição e atraída para armadilhas com frutas em decomposição.

108(74) Smyrna blomfildia (Fabricius, [1782])

Fevereiro, março, agosto, outubro e dezembro. Comum, em mata primária, atraída para armadilhas com frutas em decomposição.

Biblidini (Boisduval, 1833) Harvey, 1991 (30)

109(75) Biblis hyperia nectanabis (Fruhstorfer, 1909)

Fevereiro, março, maio, agosto e dezembro. Comum, em mata primária, atraída para armadilhas com frutas em decomposição.

110(76) Mestra dorcas apicalis (Staudinger, 1886)

Fevereiro. Rara, em áreas semi-abertas na estrada para o Porto.

111(77) Catonephele acontius acontius (Linnaeus, 1758)

Fevereiro, março, agosto, outubro e dezembro. Comum, em mata primária, pousada em excrementos e atraída para armadilhas com frutas em decomposição.

112(78) Catonephele numilia penthia (Hewitson, 1852)

Fevereiro, março, agosto, outubro e dezembro. Comum, em mata primária, pousada em excrementos e atraída para armadilhas com frutas em decomposição.

113(79) Eunica bechina bechina (Hewitson, 1852)

Maio. Rara, em áreas semi-abertas na Trilha do Mico Leão.

114(80) Eunica eburnea Fruhstorfer, 1907

Agosto. Rara, em areia.

115(81) Eunica eurota dolores (Prittwitz, 1871)

Fevereiro. Rara, em areia.

116(82) Eunica maja maja (Fabricius, 1775)

Fevereiro, março, maio, agosto, outubro e dezembro. Comum, em mata primária. 


\section{7(83) Eunica margarita (Godart, [1824])}

Fevereiro, março, maio, agosto e outubro. Comum, em mata primária e areia.

118(84) Eunica tatila bellaria Fruhstorfer, 1908

Fevereiro, março, agosto e outubro. Comum, em mata primária.

119(85) Ectima thecla thecla (Fabricius, 1796)

Fevereiro e março. Escassa, em mata primária.

120(86) Hamadryas amphinome amphinome (Linnaeus, 1767)

Fevereiro, março, agosto, outubro e dezembro. Comum, em mata primária, atraída para armadilhas com frutas em decomposição

121(87) Hamadryas arete (Doubleday, 1847)

Fevereiro, março e outubro. Comum, em mata primária.

122(88) Hamadryas epinome epinome (C. Felder \& R. Felder, 1867)

Fevereiro, março, maio, agosto, outubro e dezembro. Comum, em mata primária, atraída para armadilhas com frutas em decomposição.

123(89) Hamadryas februa februa (Hübner, 1823)

Fevereiro, março, maio, agosto, outubro e dezembro. Comum, em mata primária, atraída para armadilhas com frutas em decomposição.

124(90) Nica flavilla flavilla (Godart, [1824])

Fevereiro, março, maio, agosto, outubro e dezembro. Comum, em mata primária, atraída para armadilhas com frutas em decomposição.

125(91) Pyrrhogyra neaerea arge Gosse, 1880

Fevereiro, março, maio e agosto. Comum, em mata primária, pousada em excrementos, atraída para armadilhas com frutas em decomposição.

126(92) Temenis laothoe meridionalis Ebert, 1965

Fevereiro, março, maio, agosto, outubro e dezembro. Comum, em mata primária, pousada em excrementos, atraída para armadilhas com frutas em decomposição.

127(93) Dynamine aerata (Butler, 1877)

Fevereiro, março, maio, agosto, outubro e dezembro. Comum, em mata primária, pousada em excrementos, atraída para armadilhas com frutas em decomposição.

128(94) Dynamine agacles (Dalman, 1823)

Fevereiro, março, maio, agosto, outubro e dezembro. Comum, em mata primária, pousada em excrementos, atraída para armadilhas com frutas em decomposição.

129(95) Dynamine artimisia artimisia (Fabricius, 1793)

Fevereiro, março, maio, agosto, outubro e dezembro. Comum, em mata primária.

130(96) Dynamine coenus coenus (Fabricius, 1793)

Fevereiro. Rara, em mata primária na estrada para o Porto. 
131(97) Dynamine mylitta mylitta (Cramer, [1779])

Fevereiro, março, agosto, outubro e dezembro. Comum, em mata primária, atraída para armadilhas com frutas em decomposição.

132(98) Dynamine tithia tithia (Hübner, 1823)

Fevereiro, março, maio e dezembro. Comum, em mata primária.

133(99) Callicore astarte codomanus (Fabricius, [1782])

Fevereiro, maio, agosto, outubro e dezembro. Comum, em mata primária e areia.

134(100) Callicore hydaspes (Drury, 1782)

Fevereiro, maio, agosto, outubro e dezembro. Comum, em mata primária e areia.

135(101) Callicore pygas thamyris (Ménétriés, 1857)

Fevereiro, março, maio, agosto, outubro e dezembro. Comum, em mata primária e areia.

136(102) Callicore sorana sorana (Godart, [1824])

Agosto e outubro. Comum, em áreas semi-abertas.

137(103) Callidula pyrame pyrame Hübner, [1819]

Fevereiro, março, maio, agosto, outubro e dezembro. Comum, em mata primária e areia.

138(104) Diaethria clymena janeira (C. Felder, 1862)

Fevereiro, maio, agosto e dezembro. Comum, em mata primária e areia.

Limenitidini (Behr, 1864) Harvey, 1991 (6)

139(105) Adelpha abia (Hewitson, 1850)

Dezembro. Rara, em mata primária.

140(106) Adelpha aethalia davisii (Butler, 1877)

Outubro. Rara, em mata primária no Porto.

141(107) Adelpha ampla mincia Hall, 1938

Maio, agosto, outubro e dezembro. Comum, em mata primária.

142(108) Adelpha cytherea aea (C. Felder \& R. Felder, 1867)

Maio. Rara, em mata primária no Porto.

143(109) Adelpha phylaca goyama Schaus, 1902

Fevereiro, março e maio. Comum, em mata primária, sobre excrementos e carcaças de animais.

144(110) Adelpha plesaure plesaure Hübner, 1823

Fevereiro, março, maio e outubro. Comum, em mata primária.

Cyrestidini (Guenée, 1865) Harvey, 1991 (2)

145(111) Marpesia chiron marius (Cramer, [1780])

Fevereiro, março, maio, agosto, outubro e dezembro. Comum, em mata primária e areia.

146(112) Marpesia petreus petreus (Cramer, [1776])

Fevereiro, março, agosto, outubro e dezembro. Comum, em mata primária e areia. 
Apaturinae (Boisduval, 1840) Kirby, 1870 (3)

147(113) Doxocopa agathina vacuna (Godart, 1824)

Fevereiro, março, agosto, outubro e dezembro. Comum, em mata primária e areia.

148(114) Doxocopa laure griseldis (C. Felder \& R. Felder, 1862)

Março e outubro. Escassa, em mata primária no topo do Morro.

149(115) Doxocopa linda mileta (Boisduval, 1870)

Fevereiro, março, agosto, outubro e dezembro. Comum, em mata primária e areia.

Charaxinae (Guenée, 1865) Grote, 1897 (12)

150(116) Archaeoprepona demophon thalpius (Hübner, [1814])

Fevereiro, março, agosto, outubro e dezembro. Comum, em mata primária, pousada em excrementos, atraída para armadilhas com frutas em decomposição.

151(117) Archaeoprepona demophoon antimache (Hübner, [1819])

Fevereiro, agosto, outubro e dezembro. Comum, em mata primária, pousada em excrementos, atraída para armadilhas com frutas em decomposição.

152(118) Fountainea halice halice (Godart, [1824])

Fevereiro, março e agosto. Escassa, em mata primária.

153(119) Fountainea ryphea phidile (Geyer, 1834)

Fevereiro, março, agosto, outubro e dezembro. Comum, em mata primária, pousada em excrementos, atraída para armadilhas com frutas em decomposição.

154(120) Hypna clytemnestra huebneri Butler, 1866

Fevereiro, março, agosto e dezembro. Comum, em mata primária, atraída para armadilhas com frutas em decomposição.

155(121) Memphis appias (Hübner, 1825)

Fevereiro, agosto e dezembro. Comum, em mata primária, excrementos, carcaças de animais, atraída para armadilhas com frutas em decomposição.

156(122) Memphis moruus stheno (Prittwitz, 1865)

Fevereiro, março, maio, agosto, outubro e dezembro. Comum, em mata primária, excrementos, carcaças de animais, atraída para armadilhas com frutas em decomposição.

157(123) Memphis polyxo (H. Druce, 1874)

Fevereiro. Rara, em mata primária no Porto.

158(124) Prepona eugenes diluta Fruhstorfer, 1904

Fevereiro, março e outubro. Rara, em mata primária nas proximidades da Sede, sobre excrementos.

159(125) Prepona laertes laertes (Hübner, [1811])

Fevereiro. Rara, em mata primária nas proximidades da Sede, sobre excrementos. 
160(126) Prepona pheridamas (Cramer, [1777])

Outubro. Rara, em mata primária.

161(127) Zaretis itys strigosus (Gmelin, 1790)

Fevereiro, março, agosto, outubro e dezembro. Comum, em mata primária, pousada em excrementos, atraída para armadilhas com frutas em decomposição.

Libytheinae (Boisduval, 1833) Bates, 1861 (1)

162(128) Libytheana carinenta carinenta (Cramer, [1777])

Fevereiro, março, maio, agosto e outubro. Comum, em mata primária e áreas semi-abertas.

Riodinidae Grote, 1895 (33)

Euselasiinae (Kirby, 1871) Stichel, 1928 (1)

163(1) Euselasia crinon crinon Stichel, 1919

Fevereiro e outubro. Rara, em mata primária.

Riodininae Grote, 1895 (31)

Eurybiini Stichel, 1910 (7)

164(2) Leucochimona philemon mathata (Hewitson, 1873)

Fevereiro e dezembro. Comum, em mata primária.

165(3) Mesosemia rhodia (Godart, [1824])

Agosto. Escassa, em mata primária.

166(4) Mesosemia bella Sharpe, 1890

Agosto e outubro. Rara, em mata primária, no topo do Morro, entre 14

e 16 horas.

167(5) Eurybia halimede emidiata Stichel, 1915

Agosto e dezembro. Escassa, em mata primária.

168(6) Alesa prema (Godart, [1824])

Fevereiro, março, agosto, outubro e dezembro. Escassa, em mata primária no topo do Morro.

169(7) Cremna thasus thasus (Cramer, [1780])

Fevereiro. Rara, em mata primária.

170(8) Cremna actoris cuyabaensis Talbot, 1928

Fevereiro. Rara, em mata primária.

Riodinini (Grote, 1895) Fruhstorfer, 1914 (21)

171(9) Rhetus periander arthurianus (Sharpe, 1890)

Fevereiro e outubro. Rara, em mata primária no Porto.

172(10) Chorinea amazon (Saunders, 1858)

Março. Rara, em mata primária no Porto.

173(11) Notheme erota angellus Stichel, 1910

Fevereiro, março, maio, agosto, outubro e dezembro. Comum, em mata primária e areia.

174(12) Calephelis brasiliensis McAlpine, 1971

Fevereiro e março. Comum, em áreas abertas. 
175(13) Parcella amarynthina (C. Felder \& R. Felder, 1865)

Fevereiro, março, maio e outubro. Escassa, em mata primária e areia.

176(14) Charis cleonus cleonus (Stoll, 1782)

Fevereiro e Março. Comum, em mata primária.

177(15) Caria marsyas Godman, 1903

Agosto. Rara, em areia no Porto.

178(16) Lasaia agesilas esmeralda Clench, 1972

Fevereiro, março, maio, agosto, outubro e dezembro. Comum, em mata primária e areia.

179(17) Amarynthis meneria meneria (Cramer, [1776])

Agosto. Escassa, em mata primária.

180(18) Melanis electron auriferax (Stichel, 1910)

Fevereiro e dezembro. Escassa, em mata primária.

181(19) Melanis marathon charon (Butler, 1874)

Fevereiro, maio e agosto. Escassa, em mata primária.

182(20) Mesene hya guttula Stichel, 1916

Fevereiro, maio e agosto. Escassa, em mata primária na Trilha do Mico Leão.

183(21) Mesene sp.

Maio. Rara, em mata primária.

184(22) Phaenochitonia sophistes (Bates, 1868)

Maio e agosto. Rara, em mata primária.

185(23) Anteros formosus formosus (Cramer, [1777])

Março. Rara, em mata primária no início da estrada para o Porto às 15 horas.

186(24) Emesis diogenia Prittwitz, 1865

Fevereiro, março e outubro. Rara, em mata primária na estrada para o

Porto.

187(25) Emesis lucinda condigna Stichel, 1925

Fevereiro. Rara, em mata primária.

188(26) Emesis russula Stichel, 1910

Agosto. Escassa, em mata primária.

189(27) Adelotypa malca (Schaus, 1902)

Agosto. Rara, em mata primária.

190(28) Adelotypa sp. (prox. A. tinea (Bates, 1868))

Maio. Rara, em mata primária.

Nymphidiini Stichel, 1911 (5)

191(29) Juditha molpe molpe (Hübner, [1819])

Março. Rara, em mata primária.

192(30) Synargis calyce brennis (Stichel, 1910)

Fevereiro, março e agosto. Escassa, em mata primária. 
193(31) Synargis ochra (Bates, 1868)

Maio. Rara, em mata primária na estrada para o Porto.

194(32) Nymphidium azanoides azanoides Butler, 1867

Março e maio. Rara, em mata primária.

195(33) Nymphidium lisimon epiplatea Butler, 1867

Fevereiro, março e dezembro. Comum, em mata primária.

Lycaenidae (Leach, 1815) Stephens, 1829 (35)

Polyommatinae (Swainson, 1827) Eliot, 1973 3)

Polyommatini (Swainson, 1827) Seitz, 1909 (3)

196(1) Hemiargus hanno (Stoll, [1780])

Fevereiro. Escassa, em áreas abertas.

197(2) Leptotes cassius (Cramer, [1775])

Fevereiro, outubro e dezembro. Escassa, em áreas abertas.

198(3) Zizula cyna tulliola (Godman \& Salvin, 1887)

Fevereiro e março. Escassa, em áreas abertas.

Theclinae (Swainson, 1831) Butler, 1869 (32)

Eumaeini (Doubleday, 1847) Eliot, 1973 (32)

199(4) Arcas imperialis (Cramer, [1775])

Fevereiro. Rara, em mata primária na estrada para o Porto.

200(5) Arawacus separata (Lathy, 1926)

Fevereiro e dezembro. Rara, em mata primária na estrada para o Porto.

201(6) Calycopis chacona (Jörgensen, 1932)

Maio e dezembro. Comum, em mata primária.

202(7) Calycopis devia (Möschler, 1883)

Dezembro. Escassa, em mata primária.

203(8) Chalybs hassan (Stoll, 1790)

Março. Rara, em mata primária no topo do Morro.

204(9) Chlorostrymon telea (Hewitson, 1868)

Fevereiro. Rara, em mata primária no topo do Morro.

205(10) Cyanophrys amyntor (Cramer, [1775])

Dezembro. Rara, em mata primária.

206(11) Electrostrymon endymion (Holland, 1931)

Março. Rara, em mata primária na Trilha do Mico Leão.

207(12) Lamprospilus orcidia (Hewitson, 1874)

Março. Rara, em mata primária no topo do Morro.

208(13) Magnastigma hirsuta (Prittwitz, 1865)

Março. Rara, em mata primária na estrada para o Porto.

209(14) Ministrymon azia (Hewitson, 1873)

Março. Rara, em mata primária no topo do Morro.

210(15) Ocaria ocrisia (Hewitson, 1868)

Março, outubro e dezembro. Escassa, em areia. 
211(16) Paiwarria venulius (Cramer, [1779])

Março. Rara, em mata primária no topo do Morro.

212(17) Panthiades phaleros (Linnaeus, 1767)

Março. Escassa, em mata primária.

213(18) Pseudolycaena marsyas marsyas (Linnaeus, 1758)

Maio. Rara, em mata primária na estrada para o Porto e Trilha do Mico Leão.

214(19) Rekoa malina (Hewitson, 1867)

Março. Rara, em mata primária.

215(20) Rekoa meton (Cramer, [1779])

Fevereiro. Rara, em mata primária na estrada para o Porto.

216(21) Strymon astiocha (Prittwitz, 1865)

Fevereiro e Maio. Rara, em mata primária.

217(22) Strymon cydia (Hewitson, 1874)

Março. Rara, em mata primária.

218(23) Strymon molucha (Hewitson, 1867)

Fevereiro e maio. Rara, em áreas semi-abertas.

219(24) Strymon megarus (Godart, [1824])

Dezembro. Rara, em mata primária.

220(25) Theritas triquetra (Hewitson, 1865)

Maio. Rara, em mata primária na estrada para o Porto.

221(26) "Thecla sp." (próx.T. caninius H. H. Druce, 1907)

Março e dezembro. Escassa, em mata primária.

222(27) "Thecla" celmus (Cramer, [1775])

Fevereiro e dezembro. Escassa, em mata primária e áreas semi-abertas. 223(28) "Thecla" emessa Hewitson, 1867

Março. Rara, em mata primária no topo do Morro.

224(29) "Thecla" gargophia Hewitson, 1877

Março. Rara, em mata primária no topo do Morro.

225(30) "Thecla" hemon (Cramer, [1775])

Março, outubro e dezembro. Escassa, em mata primária.

226(31) "Thecla" ligurina Hewitson, 1874

Maio. Rara, em mata primária.

227(32) "Thecla" orobia Hewitson, 1867

Fevereiro. Rara, em mata primária.

228(33) "Thecla" panchaea Hewitson, 1867

Março. Rara, em mata primária.

229(34) "Thecla" phydela Hewitson, 1867

Maio. Rara, em mata primária.

230(35) "Thecla" tephraeus (Geyer, 1837)

Fevereiro, março e dezembro. Rara, em mata primária no topo do Morro. 


\section{Hesperioidea (Latreille, 1809) J.H. Comstock \&} A.B. Comstock, 1904 (196)

Hesperiidae (Latreille, 1809) Stephens, 1828 (196)

Pyrrhopyginae (Mabille, 1877) Watson, 1893 (10)

231(1)Pyrrhopyge aziza subnubilus Hayward, 1935, nom. rev., stat. n., comb. rev.

Pyrrhopyge subnubilus Hayward, 1935. Rev. Soc. Ent. Arg. 7:125; holótipo fềmea, Puerto Bemberg, Misiones, Argentina.

Elbella mariae; Evans, 1951. Cat. Amer. Hesp. 1, p.42; part. syn.: subnubilus.

Elbella subnubilus: Hayward, 1973. Op. Lill. 23:13.

O exame do holótipo de $P$. subnubilus, depositado no Museu de La Plata, La Plata, Argentina, mostrou tratar-se de uma subespécie de Pyrrhopyge aziza, dentro do conceito de Evans (1951, p.11). O grupo como um todo necessita de uma revisão.

Esta subespécie também ocorre em : São Paulo: Rio Claro, Itapetininga, Ribeirão Preto e Minas Gerais: Pouso Alegre. Março. Rara, em mata primária na Trilha do Mico Leão.

232(2) Elbella intersecta intersecta (Herrich-Schäffer, 1869)

Março e outubro. Rara, em areia.

233(3) Elbella blanda Evans, 1951

Março e dezembro. Comum, em mata primária no topo do Morro, voando e pousando a aproximadamente 6 metros do solo.

234(4) Parelbella ahira extrema (Röber, 1925)

Fevereiro, outubro e dezembro. Comum, em mata primária no topo do Morro, voando e pousando a aproximadamente 6 metros do solo, na subcopa de árvores.

235(5) Zonia zonia diabo, ssp.n. (Fig. 2)

Outubro e dezembro. Comum, em mata primária na parte nordeste do Morro, voando a proximadamente 15 metros do solo, mas pousando sobre folhas de árvores de 3 metros de altura. A captura em vôo só foi possível quando o vento forte trazia os exemplares para a proximidade da rede entomológica.

EVANS (1951) descreveu o gênero e a espécie baseado em um exemplar masculino de Tefé, Amazonas, Brasil. Nicolay (1975) descreveu e figurou a subespécie Zonia zonia panamensis, baseada em cinco exemplares do Panamá; ainda figurou o holótipo de Zonia zonia zonia.

Os exemplares coletados no Parque Estadual do Morro do Diabo, assim como dois outros de Goiás: Pirenópolis, diferem das duas subespécies mencionadas acima, razão de sua descrição a seguir como subespécie nova.

Macho: Comprimento da asa anterior: 26-28 mm. Padrão dos desenhos como nas demais subespécies, diferindo pelos seguintes caracteres: mancha apical do espaço R2-R3 grande, como em R3-R4 e normalmente inserida no conjunto das manchas apicais, quando um tanto separada, então a distância entre as manchas em 
R2-R3 e R3-R4 menor que o comprimento da primeira; a mancha em M3-CuA1 e a faixa mediana entre a costa e $\mathrm{CuA} 2-2 \mathrm{~A}$ mais largas, sendo a mancha em $\mathrm{Cu} 1-\mathrm{CuA} 2$ mais larga que alta.

Fêmea: desconhecida.

Holótipo macho com as seguintes etiquetas: $122-25-\mathrm{X}-1987$, Morro do Diabo, Teodoro Sampaio, SP, 300-600m, Mielke \& Casagrande/Holotypus/ Holótipo Zonia zonia diabo Mielke \& Casagrande, O. Mielke det. 1997/ 17.893/. Coleção Mielke no Departamento de Zoologia, Universidade Federal do Paraná.

Parátipos: 3 machos com os mesmos dados do holótipo; 10 machos, 5-8-XII1989 e 2 machos 15-18-III-1991 com a mesma procedência do holótipo, coleção do Departamento de Zoologia, Universidade Federal do Paraná; 2 machos 23-IV-1992, Pirenópolis, Goiás, Brasil, V.O.Becker leg., na mesma coleção do holótipo.

Etimologia: o nome é alusivo ao Morro do Diabo, local da coleta.
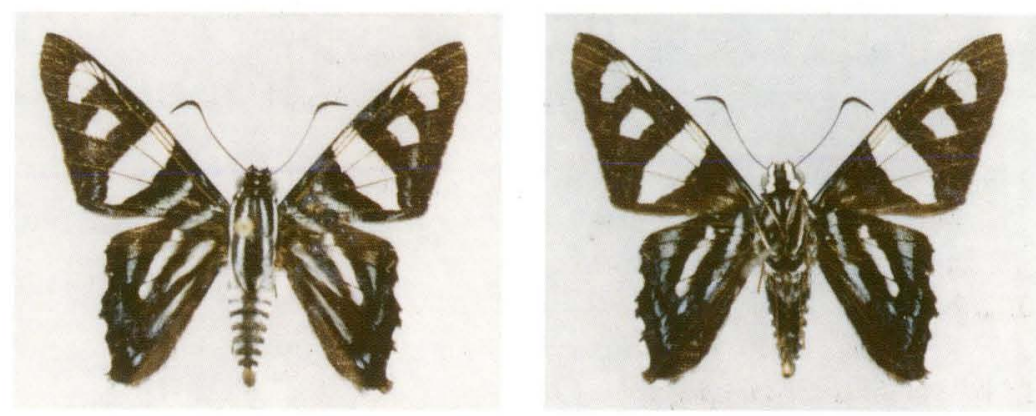

Fig. 02. Zonia zonia diabo ssp.n., holótipo macho, faces dorsal e ventral.

236(6) Jemadia gnetus (Fabricius, 1782)

Outubro. Rara, uma fêmea em mata primária no topo do Morro.

237(7) Mimoniades versicolor versicolor (Latreille, [1824])

Fevereiro, março e outubro. Escassa, em mata primária e areia.

238(8) Mysoria barcastus barta Evans, 1951

Fevereiro, outubro e dezembro. Escassa, em areia.

239(9) Myscelus amystis epigona Herrich-Schäffer, 1869

Agosto, outubro e dezembro. Comum, em mata primária no topo do Morro.

240(10) Passova polemon (Hopffer, 1874)

Março e dezembro. Rara, em mata primária na estrada para o Porto.

Pyrginae (Burmeister, 1878) Lindsey, 1928 (89)

Eudamini (Mabille, 1878)(42)

241(11) Phocides pialia pialia (Hewitson, 1857)

Fevereiro. Rara, em mata primária na base do Morro. 
242(12) Phocides polybius phanias (Burmeister, 1879)

Agosto. Escassa, em mata primária.

243(13) Phocides thermus valgus (Mabille, 1883)

Outubro. Rara, em areia.

244(14) Phocides charon (C. Felder \& R. Felder, 1859)

Fevereiro, março, agosto e dezembro. Comum, em mata primária no topo do Morro e areia.

245(15) Drephalys helixus helixus (Hewitson, 1877)

Março, outubro e dezembro. Rara, em mata primária no topo do Morro, voando pela manhã, entre 9 e 10 horas.

246(16) Udranomia kikkawai (Weeks, 1906)

Março. Rara, em mata primária no topo do Morro.

247(17) Augiades epimethea epimethea (Plötz, 1883)

Agosto e dezembro. Rara, em mata primária na base do Morro.

248(18) Proteides mercurius mercurius (Fabricius, 1787)

Fevereiro, outubro e dezembro. Escassa, em mata primária na base do Morro e areia.

249(19) Epargyreus socus socus Hübner, [1825]

Fevereiro, março, agosto, outubro e dezembro. Comum, em mata primária no topo do Morro.

250(20) Polygonus leo leo (Gmelin, 1790)

Fevereiro, março, maio e outubro. Comum, em mata primária.

251(21) Chrysoplectrum bahiana bahiana (Herrich-Schäffer, 1869)

Fevereiro e outubro. Rara, em mata primária na estrada para o Porto.

252(22) Chrysoplectrum orphne (Plötz, 1882)

Março. Rara, em mata primária no topo do Morro.

253(23) Aguna asander asander (Hewitson, 1867)

Fevereiro, março e agosto. Comum, em mata primária.

254(24) Aguna megacles megacles (Mabille, 1888)

Outubro e dezembro. Rara, em mata primária no topo do Morro.

255(25) Typhedanus stylites (Herrich-Schäffer, 1869)

Agosto. Rara, em mata primária na estrada para o Porto.

256(26) Typhedanus undulatus (Hewitson, 1867)

Fevereiro. Rara, em mata primária na estrada para o Porto.

257(27) Typhedanus crameri McHenry, 1960

Fevereiro, março e outubro. Escassa, em mata primária no topo do Morro.

258(28) Polythrix octomaculata octomaculata (Sepp, [1844])

Fevereiro, março, outubro e dezembro. Escassa, em mata primária no topo do Morro e na estrada para o Porto.

259(29) Polythrix caunus (Herrich-Schäffer, 1869)

Fevereiro, março, maio, agosto e dezembro. Comum, em mata primária no topo do Morro. 
260(30) Urbanus proteus proteus (Linnaeus, 1758)

Fevereiro, março, maio, agosto e dezembro. Comum, em mata primária e áreas semi-abertas.

261(31) Urbanus belli (Hayward, 1935)

Março e outubro. Rara, em mata primária no topo do Morro.

262(32) Urbanus esta Evans, 1952

Fevereiro, março e outubro. Comum, em mata primária no topo do Morro.

263(33) Urbanus dorantes dorantes (Stoll, 1790)

Fevereiro, março, maio, agosto, outubro e dezembro. Comum, em mata primária.

264(34) Urbanus teleus (Hübner, 1821)

Março, agosto e outubro. Escassa, em áreas semi-abertas.

265(35) Urbanus simplicius (Stoll, 1790)

Março e maio. Escassa, em mata primária no topo do Morro e áreas semi-abertas na Trilha do Mico Leão.

266(36) Urbanus procne (Plötz, 1880)

Fevereiro. Rara, em mata primária no Porto.

267(37) Urbanus albimargo rica Evans, 1952

Fevereiro, março, agosto e outubro. Comum, em mata primária.

268(38) Urbanus doryssus albicuspis (Herrich-Schäffer, 1869)

Dezembro. Rara, em mata primária na estrada para o Porto.

269(39) Urbanus virescens (Mabille, 1877)

Fevereiro, março, agosto, outubro e dezembro. Comum, em mata primária.

270(40) Urbanus chalco (Hübner, 1823)

Fevereiro. Rara, em mata primária no topo do Morro.

271(41) Astraptes fulgerator fulgerator (Walch, 1775)

Fevereiro, março, agosto e outubro. Comum, em mata primária.

272(42) Astraptes fulgor (Hayward, 1938)

Agosto e outubro. Rara, em mata primária na base do Morro.

273(43) Astraptes aulus (Plötz, 1881)

Março, outubro e dezembro. Escassa, em mata primária no topo do Morro.

274(44) Astraptes creteus siges (Mabille, 1903)

Outubro. Rara, em mata primária na estrada para o Porto.

275(45) Astraptes cretatus adoba Evans, 1952

Março. Rara, em mata primária no topo do Morro.

276(46) Astraptes anaphus anaphus (Cramer, [1779])

Março e agosto. Escassa, em mata primária no topo do Morro e na estrada para o Porto.

277(47) Dyscophellus porcius doriscus (Hewitson, 1867)

Fevereiro. Rara, em mata primária nas proximidades da sede, pousada 
em areia úmida, no crepúsculo.

278(48) Dyscophellus ramusis damias (Plötz, 1882)

Fevereiro. Rara, em mata primária, no crepúsculo.

279(49) Nascus phocus (Cramer, [1777])

Fevereiro e dezembro. Rara, em mata primária na estrada para o Porto, no crepúsculo.

280(50) Nascus paulliniae (Sepp, 1842)

Outubro. Rara, em mata primária.

281(51) Cephise orima (Schaus, 1902)

Fevereiro. Rara, em mata primária no estrada para o Porto, no crepúsculo.

282(52) Celaenorrhinus similis similis Hayward, 1933

Março, maio e agosto. Comum, em mata primária.

Pyrgini (Burmeister, 1878) Orfila, 1950 (49)

283(53) Spathilepia clonius (Cramer, [1775])

Outubro. Rara, em mata primária.

284(54) Cogia calchas (Herrich-Schäffer, 1869)

Agosto. Rara, em áreas semi-abertas na Trilha do Mico Leão.

285(55) Telemiades meris meris (Plötz, 1886) sp. rev.

Arteurotia meris Plötz, 1886 (Möschler in litt.). Stett. Ent. Ztg. 47: 87; Colombia

Telemiades meris, cujo "tipo" foi examinado no "Museum für Naturkunde", Berlin, Alemanha, possui a genitália masculina semelhante a de T. m. brazus Bell, 1949, e muito diferente de T. nicomedes (Möschler, 1879), cujo "tipo" foi examinado no mesmo museu. Em T. m. brazus, que ocorre na Mata Atlântica entre o Espírito Santo e Santa Catarina, no sudeste do Brasil, a ponta da valva é pouco mais alongada, como na figura da descrição original. $T$. nicomedes é muito semelhante à T. meris, porém a genitália masculina é como figurada por EVANS (1953, pl.27). T. meris meris ocorre no PANAMÁ: Canal Zone, Gamboa, ColômBIA: Chocó, Rio San Juan, Valle, Rio Achicaya e no BRAsil: Acre, Taumaturgo, Rondônia, Cacaulândia, Cadeias do Jamari, Santa Catarina, Seara, São Paulo, Teodoro Sampaio, enquanto que T. m. brazus no Brazil: Espírito Santo, Conceição da Barra, Linhares, Minas Gerais, Ibirité, Paracatu, Rio de Janeiro, Imbariê, Niteroi, Rio de Janeiro, Santa Catarina, Joinville, São Bento do Sul.

Março e outubro. Rara, em mata primária no topo do Morro, voando a aproximadamente 1,5 metros do solo.

286(56) Telemiades amphion misitheus Mabille, 1888

Fevereiro. Rara, em mata primária na estrada para o Porto.

287(57) Polyctor polyctor polyctor (Prittwitz, 1868)

Fevereiro, março, maio, agosto, outubro e dezembro. Comum, em mata primária. 
288(58) Nisoniades macarius (Herrich-Schäffer, 1870)

Fevereiro. Escassa, em mata primária no Porto.

289(59) Nisoniades castolus (Hewitson, 1878)

Maio e agosto. Rara, em mata primária na estrada para o Porto.

290(60) Nisoniades bipuncta (Schaus, 1902)

Outubro. Rara, em mata primária e areia.

291(61) Pellicia costimacula hebe Hayward, 1938

Fevereiro, março, maio, agosto e outubro. Comum, em mata primária e areia.

292(62) Pellicia ranta rancida Evans, 1953

Fevereiro, março e outubro. Escassa, em areia no Porto.

293(63) Pellicia najoides Hayward, 1933

Fevereiro, maio, agosto e outubro. Comum, em areia no Porto.

294(64) Viola violella (Mabille, 1898)

Fevereiro, março, maio e outubro. Comum, em áreas semi-abertas

próximas ao Porto e na Trilha do Mico Leão.

295(65) Trina geometrina geometrina (C. Felder \& R. Felder, 1867)

Fevereiro, março, maio, outubro e dezembro. Comum, em mata primária.

296(66) Gorgythion begga begga (Prittwitz, 1868)

Fevereiro, março, maio, agosto, outubro e dezembro. Comum, em mata primária.

297(67) Gorgythion beggina escalophoides Evans, 1953

Março e maio. Rara, em mata primária na base do Morro.

298(68) Staphylus minor minor Schaus, 1902

Março. Rara, em mata primária na estrada para o Porto.

299(69) Staphylus incisus (Mabille, 1878)

Fevereiro, março, agosto, outubro e dezembro. Comum, em mata primária.

300(70) Staphylus chlorocephala (Latreille, [1824])

Fevereiro e dezembro. Rara, em mata primária na estrada para o Porto.

301(71) Staphylus melangon epicaste Mabille, 1903

Fevereiro, março, maio e outubro. Comum, em mata primária.

A data de publicação do nome subespecífico é de 1903, pois na publicação de 1878 o gênero não foi indicado (ICZN, Art. 11 h III).

302(72) Quadrus cerialis (Stoll, 1782)

Fevereiro, março e outubro. Comum, em mata primária.

303(73) Quadrus u-lucida mimus (Mabille \& Boullet, 1917) nom. rev., stat. nov.

Pythonides mimus Mabille \& Boullet, 1917. Bull. Soc. ent. France (1916), p.321, 1 fêmea, Brasil, Museu de Paris; 1 macho Paraguai, Coleção Boullet do Museu de Paris; 1 macho Rio Grande do Sul, Brasil, Coleção Mabille. 
Os exemplares do sul de Minas Gerais (Cambuquira), São Paulo (São Paulo, Teodoro Sampaio), Rio Grande do Sul, Oeste do Paraná, Santa Catarina e Paraguai, possuem a face ventral da asa posterior de um azul claro, ao invés de branco como em Q. u-lucida u-lucida (Plötz, 1884), razão da revalidação.

Agosto. Rara, em mata primária na Trilha do Mico Leão.

304(74) Zera hyacinthus servius (Plötz, 1884)

Outubro. Rara, em mata primária na Trilha do Mico Leão.

305(75) Pythonides jovianus fabricii Kirby, 1871

Fevereiro e março. Escassa, em mata primária na estrada para o Porto e na base do Morro.

306(76) Sostrata bifasciata bifasciata (Ménétriés, 1829)

Fevereiro, março, outubro e dezembro. Comum, em mata primária na estrada para o Porto.

307(77) Mylon menippus (Fabricius, 1775)

Fevereiro, março, maio, agosto e dezembro. Comum, em mata primária e areia.

308(78) Mylon pelopidas (Fabricius, 1793)

Fevereiro e outubro. Escassa, em areia no Porto.

309(79) Xenophanes tryxus (Stoll, [1780])

Fevereiro e agosto. Escassa, em mata primária na Trilha do Mico Leão. 310(80) Antigonus nearchus (Latreille, [1817])

Fevereiro, agosto, outubro e dezembro. Comum, em mata primária e areia.

311(81) Antigonus erosus (Hübner, [1812])

Fevereiro, agosto e dezembro. Comum, em mata primária e areia.

312(82) Antigonus liborius areta Evans, 1953

Maio e agosto. Escassa, em mata primária na estrada para o Porto.

313(83) Achlyodes busirus rioja Evans, 1953

Fevereiro, março, maio, outubro e dezembro. Comum, em mata primária.

314(84) Achlyodes mithridates thraso (Hübner, 1807)

Fevereiro, março, maio, agosto e outubro. Comum, em mata primária.

315(85) Grais stigmaticus stigmaticus (Mabille, 1883)

Fevereiro, março, maio e agosto. Comum, em mata primária.

316(86) Timochares trifasciata trifasciata (Hewitson, 1868)

Fevereiro e março. Rara, em mata primária no topo do Morro e na estrada para o Porto.

317(87) Anastrus sempiternus simplicior (Möschler, 1877)

Fevereiro, março, agosto e dezembro. Comum, em mata primária.

318(88) Ebrietas anacreon anacreon (Staudinger, 1876)

Fevereiro, março, maio, agosto e dezembro. Comum, em mata primária e areia. 
319(89) Helias phalaenoides palpalis (Latreille, [1824])

Fevereiro, março, maio e dezembro. Comum, em mata primária. 320(90) Camptopleura auxo (Möschler, 1879)

Fevereiro. Rara, em areia.

321(91) Chiomara asychis autander (Mabille, 1891)

Outubro. Rara, em áreas semi-abertas.

322(92) Gesta gesta gesta (Herrich-Schäffer, 1869)

Fevereiro. Escassa, em mata primária na estrada para o Porto.

323(93) Pyrgus oileus orcus (Stoll, [1780])

Fevereiro, março, maio, agosto e dezembro. Comum, em todos os ambientes, porém rara em mata primária.

324(94) Pyrgus communis orcynoides (Giacomelli, 1928)

Maio. Rara, em areia.

325(95) Heliopetes domicella willi (Plötz, 1884)

Fevereiro. Rara, em areia.

326(96) Heliopetes omrina (Butler, 1870)

Fevereiro e maio. Escassa, em mata primária e áreas semi-abertas na estrada para o Porto e na Trilha do Mico Leão.

327(97) Heliopetes arsalte arsalte (Linnaeus, 1758)

Fevereiro, março, maio, agosto e outubro. Comum, em mata primária e em áreas semi-abertas e abertas.

328(98) Heliopetes alana (Reakirt, 1868)

Outubro. Rara, em áreas semi-abertas.

329(99) Heliopetes laviana leca (Butler, 1870)

Fevereiro e agosto. Escassa, em mata primária e areia.

330(100) Heliopetes macaira orbigera (Mabille, 1888)

Agosto. Rara, em áreas semi-abertas na Trilha do Mico Leão.

Hesperiinae (Latreille, 1809) Watson, 1893 (97)

331(101) Synapte silius (Latreille, 1824)

Fevereiro, agosto, outubro e dezembro. Escassa, em mata primária na estrada para o Porto e na base do Morro.

332(102) Synapte malitiosa equa Evans, 1955

Agosto. Rara, em mata primária na base do Morro.

333(103) Zariaspes mys (Hübner, [1808])

Fevereiro, agosto e outubro. Escassa, em mata primária na base do Morro.

334(104) Anthoptus epictetus (Fabricius, 1793)

Fevereiro e março. Comum, em mata primária na estrada para o Porto e na base do Morro.

335(105) Anthoptus insignis (Plötz, 1882)

Agosto. Escassa, em mata primária na estrada para o Porto.

336(106) Corticea corticea (Plötz, 1883)

Fevereiro. Escassa, em mata primária na estrada para o Porto. 
337(107) Cantha roraimae (Bell, 1932)

Fevereiro e março. Escassa, em mata primária na estrada para o Porto. 338(108) Vinius letis (Plötz, 1883)

Fevereiro, março e dezembro. Escassa, em mata primária na estrada para o Porto e na base do Morro.

339(109) Vinius pulcherrimus Hayward, 1934

Fevereiro, março e agosto. Escassa, em mata primária na estrada para o Porto e na Trilha do Mico Leão.

340(110) Pheraeus rumba Evans, 1955

Fevereiro e maio. Escassa, em mata primária na estrada para o Porto e na Trilha do Mico Leão.

341(111) Pheraeus fastus (Hayward, 1938)

Fevereiro. Rara, em mata primária na estrada para o Porto.

342(112) Callimormus saturnus (Herrich-Schäffer, 1869)

Março. Rara, em mata primária na estrada para o Porto.

343(113) Virga austrina (Hayward, 1934)

Março. Rara, em mata primária na Trilha do Mico Leão.

344(114) Peba verames (Schaus, 1902), sp. rev., comb.n.

Callimormus verames Schaus, 1902. Proc. U.S. Nat. Mus. 24:456; holótipo, $\mathrm{n}^{\circ} 6063$, Peru; USNM.

Vehilius vetula; Evans, 1955. Cat. Amer. Hesp. 4, p. 140; part. syn.: verames.

Peba striata Mielke, 1968. Jour. Lep. Soc. 22: 9, figs 13, 14 (macho, dorsal, ventral), 54 (estigma), 55-58 (genitália masculina), 59 (genitália feminina); holótipo macho, 27-II-1966, Paraopeba, Minas Gerais, Brasil; Coleção Mielke. Syn. nov.

O exame do holótipo de $C$. verames, inclusive de sua genitália, mostrou ser o sinônimo senior de $P$. striata. Syn. nov.

Fevereiro. Rara, em mata primária na estrada para o Porto.

345(115) Radiatus bradus Mielke, 1968

Fevereiro e maio. Rara, em mata primária na estrada para o Porto e na Trilha do Mico Leão.

346(116) Ludens silvaticus (Hayward, 1940)

Fevereiro e março. Rara, em mata primária na estrada para o Porto.

347(117) Methionopsis ina (Plötz, 1882)

Fevereiro, março, maio, agosto e outubro. Comum, em mata primária. 348(118) Sodalia coler (Schaus, 1902)

Fevereiro, março, maio, agosto e outubro. Comum, em mata primária. 349(119) Artines aquilina (Plötz, 1882)

Fevereiro, março, agosto e outubro. Comum, em mata primária na estrada para o Porto.

350(120) Flaccilla aecas (Stoll, [1781])

Fevereiro, maio, agosto, outubro e dezembro. Comum, em mata primária na estrada para o Porto e na Trilha do Mico Leão. 
351(121) Thargella caura occulta (Schaus, 1902)

Agosto, outubro e dezembro. Escassa, em mata primária na estrada para

o Porto e na base do Morro.

352(122) Mnaseas bicolor inca Bell, 1930

Março. Rara, em mata primária na estrada para o Porto.

353(123) Phanes almoda (Hewitson, 1866)

Março e outubro. Rara, em mata primária na estrada para o Porto.

354(124) Nastra chao (Mabille, 1898)

Maio. Rara, em áreas semi-abertas na estrada para o Porto.

355(125) Cymaenes distigma (Plötz, 1882)

Março e maio. Rara, em mata primária na base do Morro.

356(126) Cymaenes tripunctus theogenis (Capronnier, 1874)

Maio. Rara, em mata primária na base do Morro.

357(127) Cymaenes gisca Evans, 1955

Fevereiro, março e maio. Comum, em mata primária.

358(128) Cymaenes laureolus loxa Evans, 1955

Fevereiro, março, maio e agosto. Comum, em mata primária na estrada para o Porto e na base do Morro.

359(129) Vehilius stictomenes stictomenes (Butler, 1877)

Fevereiro e março. Comum, em áreas semi-abertas.

360(130) Vehilius inca (Scudder, 1872)

Março e dezembro. Escassa, em áreas semi-abertas e de mata primária

na base do Morro e na Trilha do Mico Leão.

361(131) Mnasitheus gemignanii (Hayward, 1940)

Fevereiro e dezembro. Rara, em mata primária na estrada para o Porto

e na base do Morro.

362(132) Remella remus (Fabricius, 1798)

Fevereiro. Escassa, em mata primária na estrada para o Porto.

363(133) Parphorus decorus (Herrich-Schäffer, 1869)

Fevereiro e março. Escassa, em mata primária na estrada para o Porto. 364(134) Propapias proximus (Bell, 1934)

Fevereiro, março e outubro. Escassa, em mata primária na estrada para

o Porto e na base do Morro.

365(135) Papias phainis Godman, 1900

Março, maio e agosto. Escassa, em mata primária na base do Morro e na Trilha do Mico Leão.

366(136) Cobalopsis nero (Herrich-Schäffer, 1869)

Fevereiro e março. Comum, em mata primária na estrada para o Porto e na base do Morro.

367(137) Arita serra Evans, 1955

Dezembro. Rara, em mata primária na estrada para o Porto. 
368(138) Morys geisa geisa (Möschler, 1879)

Fevereiro, março, maio, agosto, outubro e dezembro. Comum, em mata primária.

369(139) Morys compta compta (Butler, 1877)

Fevereiro, março e agosto. Comum, em mata primária.

370(140) Tigasis simplex (Bell, 1930)

Fevereiro. Escassa, em mata primária na estrada para o Porto.

371(141) Vettius marcus marcus (Fabricius, 1787)

Fevereiro, março, maio, agosto e outubro. Comum, em mata primária.

372(142) Vettius fantasos fantasos (Cramer, [1780])

Fevereiro, março, agosto, outubro e dezembro. Comum, em mata primária.

373(143) Vettius lafresnaye lafresnaye (Latreille, [1824])

Março, agosto e dezembro. Escassa, em mata primária na base do Morro.

374(144) Vettius lucretius (Latreille, [1824])

Março, maio e agosto. Escassa, em mata primária.

375(145) Paracarystus hypargyra (Herrich-Schäffer, 1869)

Fevereiro, março, maio e agosto. Escassa, em mata primária na estrada para o Porto e na base do Morro.

376(146) Thoon dubius (Bell, 1932)

Fevereiro, março, outubro e dezembro. Escassa, em mata primária na estrada para o Porto.

377(147) Justinia maculata (Bell, 1930)

Fevereiro, maio, agosto, outubro e dezembro. Escassa, em mata primária.

378(148) Eutychide olympia (Plötz, 1882)

Fevereiro, março, agosto, outubro e dezembro. Escassa, em mata primária na estrada para o Porto.

379(149) Justinia sp. (próxima de J. papaea (Hewitson, 1876)

Outubro. Rara, em mata primária na estrada para o Porto.

380(150) Onophas columbaria distigma Bell, 1930

Fevereiro, março e maio. Escassa, em mata primária na estrada para o

Porto e na base do Morro.

381(151) Enosis pruinosa agassus (Mabille, 1891)

Fevereiro, março e dezembro. Escassa, em mata primária na estrada para o Porto e base do Morro.

382(152) Tisias lesieur canna Evans, 1955.

Fevereiro e dezembro. Rara, em mata primária na estrada para o Porto. 383(153) Perichares philetes adela (Hewitson, 1867)

Fevereiro e maio. Escassa, em mata primária na estrada para o Porto e Trilha do Mico Leão. 
384(154) Perichares seneca seneca (Latreille, [1824])

Fevereiro. Rara, em mata primária na estrada para o Porto. 385(155) Saturnus saturnus servus Evans, 1955

Fevereiro, outubro e dezembro. Escassa, em mata primária na estrada para o Porto.

386(156) Phlebodes campo sifax Evans, 1955

Fevereiro e outubro. Escassa, em mata primária na estrada para o Porto. 387(157) Phlebodes xanthobasis (Hayward, 1938)

Março e maio. Rara, em mata primária na estrada para o Porto. 388(158) Phlebodes sp.

Março. Rara, em mata primária na estrada para o Porto. 389(159) Decinea decinea pruda Evans, 1955

Fevereiro, maio e agosto. Escassa, em mata primária na estrada para o Porto e na base do Morro. 390(160) Decinea lucifer (Geyer, 1831)

Março. Rara, em mata primária no topo do Morro.

391(161) Cyclosma altama (Schaus, 1902)

Fevereiro e outubro. Rara, em mata primária e areia. 392(162) Mucia zygia (Plötz, 1886)

Março. Rara, em mata primária na base do Morro. 393(163) Penicula bryanti (Weeks, 1906)

Fevereiro, março e agosto. Rara, em mata primária na estrada para o Porto e na base do Morro.

394(164) Conga chydaea (Butler, 1877)

Fevereiro e março. Escassa, em mata primária na estrada para o Porto e no topo do Morro.

395(165) Hylephila phyleus phyleus (Drury, [1773])

Fevereiro. Escassa, em mata primária, áreas semi-abertas e abertas na Trilha do Mico Leão. 396(166) Politex vibex catilina (Plötz, 1886)

Fevereiro. Escassa, em mata primária e áreas semi-abertas na estrada para o Porto.

397(167) Pompeius amblyspila (Mabille, 1898)

Maio. Escassa, em áreas semi-abertas na Trilha do Mico Leão. 398(168) Pompeius pompeius (Latreille, [1824])

Fevereiro e dezembro. Escassa, em áreas semi-abertas e abertas na estrada para o Porto.

399(169) Quasimellana meridiani (Hayward, 1934)

Fevereiro, outubro e dezembro. Escassa, em areia. 400(170) Quasimellana eulogius (Plötz, 1882)

Fevereiro. Escassa, em areia. 401(171) Anatrytone perfida (Möschler, 1879)

Agosto. Rara, em áreas semi-abertas na estrada para o Porto. 
402(172) Arotis kayei (Bell, 1931)

Fevereiro, março, outubro e dezembro. Rara, em mata primária no topo do Morro.

403(173) Propertius propertius (Fabricius, 1793)

Fevereiro, março, outubro e dezembro. Escassa, em mata primária na estrada para o Porto.

404(174) Lerodea eufala eufala (Edwards, 1869)

Fevereiro. Rara, em mata primária na estrada para o Porto.

405(175) Panoquina ocola ocola (Edwards, 1863)

Fevereiro, março e dezembro. Escassa, em mata primária na estrada para o Porto.

406(176) Panoquina lucas lucas (Fabricius, 1793)

Fevereiro e dezembro. Escassa, em mata primária na estrada para o Porto. 407(177) Panoquina hecebolus (Scudder, 1872)

Fevereiro. Rara, em mata primária na estrada para o Porto. 408(178) Zenis jebus jebus (Plötz, 1882)

Março e agosto. Escassa, em mata primária na estrada para o Porto e no topo do Morro.

409(179) Nyctelius nyctelius nyctelius (Latreille, [1824])

Maio. Escassa, em mata primária na base do Morro e na Trilha do Mico Leão.

410(180) Thespieus dalman (Latreille, [1824])

Fevereiro, março e outubro. Escassa, em mata primária na estrada para

o Porto e no topo do Morro.

411(181) Thespieus aspernatus Draudt, 1923

Agosto, outubro e dezembro. Comum, em mata primária na estrada para o Porto e areia.

412(182) Vacerra bonfilius bonfilius (Latreille, [1824])

Março, maio e agosto. Escassa, em mata primária.

413(183) Vacerra caniola elva Evans, 1955

Fevereiro, março e dezembro. Escassa, em mata primária na estrada para o Porto.

414(184) Vacerra evansi Hayward, 1938

Fevereiro, maio e dezembro. Escassa, em mata primária na estrada para o Porto.

415(185) Tirynthoides virilis (Riley, 1929)

Fevereiro e dezembro. Escassa, em mata primária na estrada e na areia do Porto.

416(186) Lindra brasus brasus (Mielke, 1968)

Fevereiro e março. Escassa, em mata primária na estrada para o Porto e na base do Morro. 
417(187) Oxynthes consca (Herrich-Schäffer, 1869)

Fevereiro. Rara, em mata primária na estrada para o Porto.

418(188) Niconiades cydia (Hewitson, 1876)

Agosto. Rara, em mata primária na base do Morro.

419(189) Niconiades nikko Hayward, 1948

Maio. Rara, em mata primária na Trilha do Mico Leão.

420(190) Niconiades xanthaphes Hübner, [1821]

Março. Rara, em mata primária na estrada para o Porto.

421(191) Xeniades orchamus orchamus (Cramer, [1777])

Março e agosto. Escassa, em mata primária na Trilha do Mico Leão.

422(192) Saliana fusta Evans, 1955

Outubro. Rara, em mata primária.

423(193) Saliana longirostris (Sepp, [1840])

Março. Rara, em mata primária na estrada para o Porto.

424(194) Thracides cleanthes cleanthes (Latreille, [1824])

Fevereiro e outubro. Rara, em mata primária na estrada para o Porto.

425(195) Pyrrhopygopsis socrates socrates (Ménétriés, 1855).

Outubro. Rara, em areia.

426(196) Gen. et sp. ign.

Março. Rara, em mata primária na estrada para o Porto.

\section{CONCLUSÕES}

Tendo em vista o número de espécies coletadas e comparando-o com aquele obtido para outras áreas, conclui-se que o número é baixo. Consideram-se os seguintes aspectos: poucos pesquisadores envolvidos no trabalho; poucas coletas (25 dias) e ausência de flores, frutas, urina e/ou excrementos animais que atraem outras espécies como justificativas para o baixo número de registros.

AGRADECIMENTOS. Aos Drs. Robert K. Robbins (National Museum of Natural History, Smithsonian Institution, Washington, D.C., USA) e Curtis J. Callaghan (Bogotá, Colômbia), pela identificação de parte dos Lycaenidae e Riodinidae e ao Dr. Gerardo Lamas (Museu de Historia Natural, Lima, Peru), pela cessão do manuscrito da "Checklist" do "Atlas of Neotropical Lepidoptera", com todos os nomes para as famílias Papilionidae, Pieridae e Nymphalidae.

\section{REFERÊNCIAS BIBLIOGRÁFICAS}

Austin, G.T.; Th. C. Emmel; O.H.H. Mielke \& H.H. Schmitz (prelo). The tropical rainforest butterfly fauna of Rondonia, Brasil. Current status of investigatrions and conservation. Trop. Lep., Gainesville.

EBERT, H. 1969. On the frequency of butterflies in eastern Brazil, with a list of the butterfly fauna of Poços de Caldas, Minas Gerais. Jour. Lep. Soc. 23 (Suppl. 3): 1-48. 
EMMEL, Th. \& G.T. Austin. 1990. The tropical rain forest butterfly fauna of Rondônia: species diversity and conservation. Trop. Lep., Gainesville, 1 (1): $1-12$.

Evans, W.H. 1951. A Catalogue of the American Hesperiidae indicating the classification and nomenclature adopted in the British Museum (Natural History). Part 1. Introduction and Group A Pyrrhopyginae. London, British Museum (Natural History), X+92p.

1955. A Catalogue of the American Hesperiidae indicating the classification and nomenclature adopted in the British Museum (Natural History). Part IV. Hesperiinae and Megathyminae. London, British Museum (Natural History), V+499p.

HAYWARD, K.J. 1935. Revisión de especies argentinas de Pyrrhopyginae. Rev. Soc.

Ent. Arg. 7: 123-129.

1973. Catálogo de los ropalóceros argentinos. Op. Lill. 23: 1-328, 1 mapa. IBGE. 1993. Mapa vegetação do Brasil. IBGE.

LAMAS, G. 1981. La fauna de mariposas de la Reserva de Tambopata, Madre de Dios, Peru (Lepidoptera, Papilionoidea, Hesperioidea). Rev. Soc. Mex. Lep. 6: 23-40.

1983. Adiciones y recorrecciones a la lista de mariposas de la Reserva de Tambopata. Rev. Soc. Mex. Lep. 8: 13-24.

1985. Los Papilionoidea (Lepidoptera) de la Zona Reservada de Tambopata, Madre de Dios, Peru. I: Papilionidae, Pieridae y Nymphalidae (en parte). Rev. peruana Ent. 27: 59-73.

1994. Megadiversidad biologica. Porque hay tantas especies de mariposas en el Perú? Actas: Mes de la Ciencia y la Technologiá, Lima, 2: 3-12.

LAMAS, G.; R.K. RobBins \& D. HARveY. 1991. A preliminary survey of the butterfly fauna of Pakitza, Parque Nacional de Manu, Peru, with an estimate of its species richness. Publ. Mus. Hist. Nat., UNMSM (A), Lima, 40: 1-19.

Mabille, P. \& E. Boullet. 1917. Description d'hespérides nouveaux (Lep. Hesperiinae, Sect. B). Bull. Soc. Ent. France 1916 (20): 320-325.

MiELKE, O.H.H. 1968. Lepidoptera of Central Brazil plateau. II. New genera, species and subspecies of Hesperiidae. Jour. Lep. Soc. 22: 1-20.

Mielke, O.H.H. \& M.M. CASAGRAnde [1992]. Lepidoptera: Papilionoidea e Hesperioidea coletados na Ilha de Maracá, Alto Alegre, Roraima, parte do Projeto Maracá, com uma lista complementar de Hesperiidae de Roraima. Acta Amazonica, (1991) 21: 175-210.

NICOLAY, S.S. 1975. Illustrations and descriptiopns of some Pyrrhopyginae from Panama (Hesperiidae). Jour. Res. Lep. 13 (3): 181-190.

PLÖTZ, C. 1886. Nachtrag und Berichtigungen zu den Hesperiinen. Stett. Ent. Ztg. $47(1 / 3): 83-117$.

Robbins, R.K.; G. Lamas; O.H.H. Miel.ke; D. Harvey \& M.M. CaSagrande. 1996. Taxonomic Composition and Ecological Structure of the Species-Rich Butterfly Community at Pakitza, Parque Nacional del Manu, Perú, p.217-252. In: D.E. Wilson \& A. SAndoval (Eds). Manu / The Biodiversity of Southe- 
astern Perú. La Biodiversidad Del Sureste Del Perú. 679p.

SCHaUS, W. 1902. Descriptions of new American butterflies. Proc. U.S. Nat. Mus.

24: $383-460$.

Recebido em 22.XI.1996; aceito em 12.XI.1997 